\title{
Treatment of diffuse alveolar hemorrhage secondary to lupus erythematosus with recombinant activated factor VII administered with a jet nebulizer
}

\author{
Raúl Carrillo Esper, Isis Espinoza de los Monteros Estrada, Teresa de la Torre León*, Agustín Omar Rosales Gutiérrez \\ and Jorge Arturo Nava López
}

\begin{abstract}
Diffuse alveolar hemorrhage (DAH) is a serious pulmonary complication in patients with autoimmune diseases who are undergoing chemotherapy or have had hematopoietic stem cell transplantation. The use of recombinant factor VIla ( $\mathrm{rFVIla)}$ to treat the acute phase of DAH by endobronchial bronchoscopy has been shown to have a significant clinical impact on the survival and evolution of these patients. We report a clinical case of a patient with DAH secondary to systemic lupus erythematosus (SLE) who was treated with rFVIla administered using a jet nebulizer, obtaining an adequate hemostatic effect with immediate control of DAH and a significant improvement in gas exchange.
\end{abstract}

Keywords: Diffuse alveolar hemorrhage, DAH (recombinant activated factor VII), Systemic lupus erythematosus (SLE)

\section{Background}

Diffuse alveolar hemorrhage (DAH) is a serious pulmonary complication secondary to autoimmune diseases, chemotherapy, and stem cell transplantation. Its immunopathogenesis has been linked to the release of inflammatory cytokines, which are involved in alveolar capillary endothelial injury and inflammation. Interstitial alveolar inflammation influences the expression of the intra-alveolar tissue factor (TF), causing an increase in the markers of thrombin generation in bronchoalveolar lavage (BAL) fluid [1-5].

Pulmonary complications in systemic lupus erythematosus (SLE) may occur in $50 \%-70 \%$ of patients. Their clinical spectrum is characterized by pleuritis, interstitial pneumonitis, thromboembolism (mainly associated with antiphospholipid syndrome), nodules, bronchiolitis obliterans, infections, diaphragmatic weakness, and DAH. DAH is a rare manifestation that occurs in $2 \%$ to $5.4 \%$ of SLE patient, and it is associated with high mortality, reaching $50 \%$ to $80 \%$ [6]. DAH can even occur in patients treated with steroids and with good disease control. The

\footnotetext{
* Correspondence: teredlt9@hotmail.com

Unidad de Terapia Intensiva, Fundación Clínica Médica Sur, Puente de Piedra 150, Col. Toriello Guerra. Delegación Tlalpan, Mexico, DF 14050, Mexico
}

treatment of this complication is mainly focused on controlling the immune dysfunction and the inflammatory process, using steroids, cyclophosphamide, and plasmapheresis [6-10].

DAH treatment per se, regardless of its diverse etiology, includes the use of recombinant activated factor VII (rFVIIa), administered bronchoscopically or intravenously, but no information is yet available regarding the use of this medication inhaled using a jet micronebulizer. The aim of this paper is to report the case of a female patient with SLE and DAH who was treated during the active phase of bleeding with inhaled rFVIIa using a jet micronebulizer.

\section{Case presentation}

A 37-year-old female patient with a history of SLE and Sjögren syndrome was treated with deflazacort $30 \mathrm{mg} /$ day. The patient was admitted to the hospital with a clinical picture characterized by abdominal pain, chills, and fever. Abdominal computed tomography (CT) showed diverticulitis Hinchey III and free fluid in the pelvic cavity, and the patient underwent laparoscopic surgery, confirming 
the CT findings and detecting a sealed diverticular perforation.

Sudden tachycardia, tachypnea, hypoxemia, cough, and hemoptysis appeared in the immediate postoperative period, and the patient was transferred to the intensive care unit (ICU) with respiratory failure and generalized coarse rales on admission. The cough increased and the hemoptysis became more evident, reaching approximately $200 \mathrm{~mL}$. The patient had hypoxemia, with 86\% oxygen saturation with $100 \% \mathrm{FiO}_{2}$ by pulse oximetry. The blood gas analysis on admission was as follows: $\mathrm{pH} 7.18, \mathrm{pCO}_{2}$ $39 \mathrm{mmHg}, \mathrm{pO}_{2} 42.3 \mathrm{mmHg}$, lactate $3.3 \mathrm{mmol} / \mathrm{L}$, alveolararterial gradient $455 \mathrm{mmHg}$, and short circuits $50 \%$. Hemoglobin decreased from 10 to $7 \mathrm{~g} / \mathrm{dL}$. Chest radiographs showed bilateral pulmonary infiltrates occupying all four quadrants, confirmed by chest $\mathrm{CT}$, on the day of admission (Figure 1).

Echocardiography showed a dilated right atrium and ventricle, tricuspid regurgitation, and pulmonary artery systolic pressure of $42 \mathrm{mmHg}$. A rheumatic profile was performed with hypocomplementemia results for C3 of $21.2 \mathrm{mg} / \mathrm{dL}(70-152 \mathrm{mg} / \mathrm{dL})$ and C4 of $4.2 \mathrm{mg} / \mathrm{dL}$ (16-38 mg/dL), positive speckled pattern antinuclear antibodies (ANA) at a titer of 1:1,640, and granular cytoplasmic fluorescence. Anticentromere antibodies (antineutrophil cytoplasmic antibody (ANCA)) were c-ANCA <1:20 (neg <1:20), p-ANCA <1:20 (neg <1:20), and atypical p-ANCA $<1: 20$ (neg $<1: 20$ ); erythrocyte sedimentation rate (ESR) was $60 \mathrm{~mm} / \mathrm{h}(0-7.4 \mathrm{~mm} / \mathrm{h})$; and C-reactive protein (CRP) was $71 \mathrm{mg} / \mathrm{L}(0-20 \mathrm{mg} / \mathrm{L})$.

After the diagnosis of DAH secondary to SLE, treatment was started with rFVIIa at a dose of $50 \mu \mathrm{g} / \mathrm{kg}$ inhaled with a jet nebulizer, achieving rapid DAH control, with the disappearance of hemoptysis and a rapid increase in $\mathrm{PaO}_{2}$ and the $\mathrm{PaO}_{2} / \mathrm{FiO}_{2}$ ratio.

Three boluses of $1 \mathrm{~g}$ methylprednisolone were administered, and $500 \mathrm{mg}$ rituximab was later added to therapy. The patient's condition improved, with follow-up radiographs and a CT scan showing the resolution of the infiltrates, after 24 h (Figure 2).

\section{Discussion}

DAH is a rare complication of SLE with high mortality. The most common age of onset is around 30 years [11,12]. DAH usually occurs in patients with an established diagnosis of SLE; however, it can also be the initial manifestation of this disease [13,14].

The proposed mechanisms for DAH development include precapillary and alveolar space damage mediated by immune processes. Three different patterns have been described histopathologically: subclinical hemorrhage, capillaritis, and diffuse alveolar damage [15-18].

Most cases are associated with slight bleeding without any sign of vasculitis, interstitial inflammation, or infection; however, scientific evidence has shown an increase in the incidence of capillaritis $[19,20]$.

Patients with SLE who present a triad of hemoptysis, sudden drop in hemoglobin in 24-48 h, and new alveolar or interstitial infiltrates should be highly suspected of $\mathrm{DAH}$. The incidence of hemoptysis varies, and it is not present clinically in some cases, confirmed by bronchoscopy and bronchoalveolar lavage fluid examination that shows erythrocytes and hemosiderin-laden macrophages. DAH is associated with other symptoms and signs such as fever, dyspnea, cough, and pleural effusion. The most common extrapulmonary manifestation of SLE is renal involvement, which usually manifests as nephritis class III or IV. A higher risk of DAH has been found in patients with active renal disease, especially nephrotic syndrome. Serological analysis in these patients shows a distinctive high anti-dsDNA titer, hypocomplementemia, and anemia, as was the case in our patient. With regard to the radiographic findings, diffuse alveolar infiltrates were evident from plain radiographs and $\mathrm{CT}$, but did not involve the lung apices [6,12,19-23].

Bronchoscopy has been recommended in the case of suspicion of DAH in which clinical presentation is atypical, as it confirms the diagnosis. In subacute cases, methods such as the quantitative score of hemosiderin-laden macrophages in the BAL fluid sample or increased red blood cell counts are used [6]. Hemosiderin, a breakdown product of

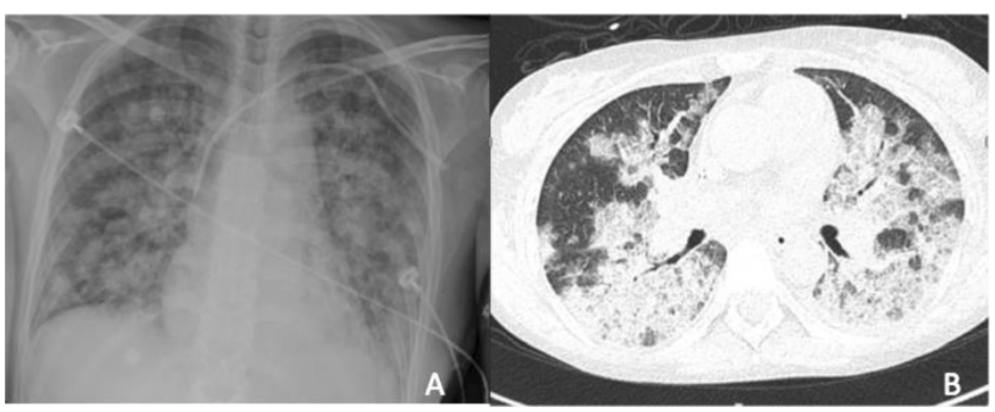

Figure 1 Chest X-ray and CT scan. (A) Chest X-ray where bilateral pulmonary infiltrates were observed. (B) Computed axial tomography (CT) scan where mixed basal pulmonary infiltrates and alveolar collapse were observed. Images were taken at the time of admission (day 1). 


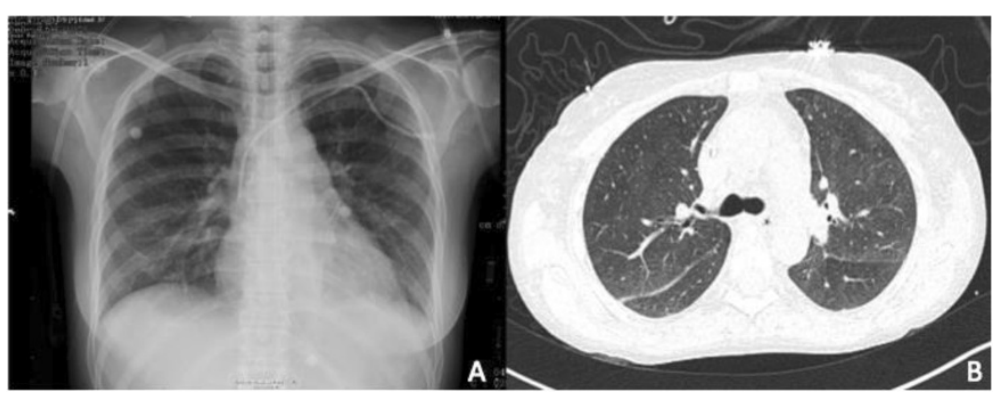

Figure $\mathbf{2}$ Chest radiography and CT scan. (A) Radiography of the chest after treatment with rFVIla, steroids, and rituximab where the resolution of pulmonary infiltrates was observed. (B) Chest CT scan where the resolution of infiltrates and alveolar collapse was confirmed (7th day).

hemoglobin, is not present in all cases in the acute and early stages, as it appears at least $48 \mathrm{~h}$ after bleeding $[24,25]$.

The treatment of DAH is based on high doses of steroids. This therapeutic approach achieves good results, especially when administered early. Cyclophosphamide or plasmapheresis can be added to the treatment when the response is not satisfactory [26,27].

Mendoza et al. [28] reviewed the treatment of patients with DAH secondary to SLE, exploring the therapeutic potential of rituximab (anti-CD20 monoclonal antibody). Most cases showed significant improvements in clinical and laboratory parameters, with good tolerance and few side effects. Thus, patients with severe lupus nephritis showed improvement in the disease activity with a significant reduction $(p<0.05)$ of proteinuria (from 3.710 to $1.786 \mathrm{~g} / \mathrm{L}, p<0.05)$. Patients with severe neurological involvement had complete symptom remission.

The rFVIIa is a medication approved for the treatment of hemorrhage in patients with hemophilia A or B who produce antibodies to FVIII or IX. FVII initiates clot formation by interaction with TF. The FVIIa-TF complex activates factor X. At high doses (80 to $100 \mathrm{mg} / \mathrm{kg}$ ), activated FVII also activates factor $\mathrm{X}$ in the absence of TF, most likely via the activation of factor $\mathrm{X}$ bound to the surface of activated platelets. Factor Xa activates prothrombin to thrombin, which in turn converts fibrinogen to fibrin $[29,30]$.

It has been proven that rFVIIa has a hemostatic effect in DAH patients of different etiologies [31-33]. Heslet et al. [34] published one case series in which they evaluated the use of rFVIIa in six patients with DAH, in which rFVIIa was instilled into the bronchial system by bronchoscopy at a dose of $50 \mu \mathrm{g} / \mathrm{kg}$ with good results, so it was decided to use this dose in our patient. Carrillo et al. [35] reported the case of a patient with $\mathrm{DAH}$ secondary to SLE who responded well to intravenous rFVIIa. Grochova et al. [36] reported a case of acute DAH secondary to stem cell transplantation, confirmed by bronchoscopy, which successfully responded to the administration of rFVIIa at a dose of $50 \mu \mathrm{g} / \mathrm{kg}$ in each of the intrapulmonary main bronchi by bronchoscopy. Dabar et al. [37] reported two DAH cases secondary to acute leukemia and granulomatous vasculitis, respectively, both successfully treated with intrabronchial rFVIIa administered by bronchoscopy. Estella et al. [38] reported two cases of DAH secondary to SLE, both successfully treated with the intrabronchial instillation of $90 \mu \mathrm{g} / \mathrm{kg}$ rVIIa by bronchoscopy. rFVIIa is a glycoprotein of 406 amino acids, has a synthetic $G_{0}$ plasma activity analogous to that of FVII, has a molecular weight of $50 \mathrm{kDa}$, and has a half-life of $3 \mathrm{~h}$. Its effect is immediate and clinical hemostasis is observed in $10 \mathrm{~min}$. It was developed in the 1980s for the treatment of bleeding in patients with congenital hemophilia with inhibitors and in some cases for patients with congenital FVII deficiency. Since the 1990s, the first series published about its use were in nonhemophiliac patients with severe hemorrhage of different etiologies $[38,39]$.

The dose of rFVIIa used in different reports is 40 $300 \mu \mathrm{g} / \mathrm{kg}$. The recommended dose in patients with microvascular bleeding is 60 to $100 \mu \mathrm{g} / \mathrm{kg}$ bolus, with a second dose after $20 \mathrm{~min}$ if they had not obtained satisfactory hemostatic control. In our work, we administered a first dose of $100 \mu \mathrm{g} / \mathrm{kg}$, and due to rebleeding, a second dose was necessary to obtain appropriate response [40].

In all published cases related to the use of rFVIIa in DAH, this medication has been administered by an intrabronchial or intravenous route. In the case of our patient, the route of administration was by inhalation using a jet micronebulizer, obtaining a favorable outcome, which opens a new opportunity and route of administration for the use of rFVIIa in DAH. This new approach is supported on the basis that hemostasis can be achieved by the interaction of rFVIIa and TF expressed at the alveolar level when an immune/inflammatory process is taking place [41].

The mechanism of action of alveolar hemostasis is primarily explained by the TF-dependent pathway, where alveolar TF is expressed during the inflammatory phase of DAH. Moreover, the tissue factor pathway inhibitor (TFPI) inhibits the local activation of factor $\mathrm{X}$ to Xa by 
the FVIIa-TF complex. In acute lung injury, the TFPI produced by alveolar macrophages can increase up to 20 times. Our observations indicate that the intrapulmonary administration of FVIIa negates TFPI's anticoagulant effect [42-44].

Clinical trials within the approved indications revealed that thrombotic events of possible or probable relationship to rFVII occurred in $0.28 \%$ of bleeding episodes treated, with the incidence within hemophilia patients with inhibitors to be $0.20 \%$, and in acquired hemophilia an incidence of $4 \%$ [45]. Patients with disseminated intravascular coagulation (DIC), advanced atherosclerotic disease, crush injury, septicemia, or concomitant treatment with activated or nonactivated prothrombin complex concentrates (aPCCs/PCCs) have an increased risk of developing thrombotic events.

Two meta-analyses of these pooled data indicate an increased risk of thrombotic events $(10.0 \%$ in patients treated with rFVIIa versus $7.5 \%$ in placebo-treated patients). Arterial thromboembolic adverse events including myocardial infarction, myocardial ischemia, cerebral infarction, and cerebral ischemia were statistically significantly increased with the use of rFVIIa compared to placebo $(5.3 \%$ to $5.6 \%$ in subjects treated with rFVIIa versus $2.8 \%$ to $3.0 \%$ in placebo-treated patients). Other arterial thromboembolic events (such as retinal artery embolism, renal artery thrombosis, arterial thrombosis of limb, bowel infarction, and intestinal infarction) have also been reported [45-49].

\section{Conclusion}

The DAH in SLE is a catastrophic complication and is associated with high morbidity and mortality. The use of rFVIIa by inhalation with a jet nebulizer is an option for the treatment of this condition, and it should always be given as a supplement to the standard treatment (methylprednisolone boluses).

\section{Consent}

The patient has given consent for the publication of accompanying documents. The authors are available for any clarification. The study was approved by the ethics committee of the Hospital Medica Sur which is governed by the Declaration of Helsinki.

\footnotetext{
Abbreviations

ANA: antinuclear antibodies; ANCA: anticentromere antibodies; BAL: bronchoalveolar lavage; CRP: C-reactive protein; CT: computed tomography; DAH: diffuse alveolar hemorrhage; ICU: intensive care unit; rFVIla: recombinant activated factor VII; SLE: systemic lupus erythematosus; TF: tissue factor; TFPI: tissue factor pathway inhibitor.
}

\section{Competing interests}

The authors declare that they have no competing interests.

\section{Authors' contributions}

RCE contributed to the conception and approval of the study. IEdIME contributed to the conception, redaction, and design of the study and the data acquisition. TdITL contributed to the redaction, design and approval of the study and the data acquisition. AORG and JANL contributed to the redaction and design of the study and the data acquisition. All authors read and approved the final manuscript.

Received: 26 November 2013 Accepted: 21 July 2014

Published: 27 August 2014

\section{References}

1. Huaringa AJ, Leyva FJ, Giralt SA, Blanco J, Signes-Costa J, Velarde H: Outcome of bone marrow transplantation patients requiring mechanical ventilation. Crit Care Med 2006, 107:10-15.

2. Agusti C, Ramirez J, Picado C, Xaubet A, Carreras E, Ballester E: Diffuse alveolar hemorrhage in allogeneic bone marrow transplantation. A postmortem study. Crit Care Med 1995, 151:1006-1110.

3. Lewis ID, Defor T, Weisdorf DJ: Increasing incidence of diffuse alveolar hemorrhage following allogeneic bone marrow transplantation: cryptic etiology and uncertain therapy. Bone Marrow Transplant 2000, 26:539-543.

4. Levi M, Van Der Poll T, Cate H, Kuipers B, Biemond BJ, Jansen HM: Differential effects of anti-cytokine treatment on bronchoalveolar hemostasis in endotoxemic chimpanzees. Am J Respir Crit Care Med 1998 158:92-98.

5. Huaringa AJ, Leyva FJ, Signes-Costa J, Morice RC, Raad I, Darwish AA: Bronchoalveolar lavage in the diagnosis of pulmonary complications of bone marrow transplantation patients. Bone Marrow Transplant 2000, 25:975-980.

6. Santiago CY, Vilá LM: Pulmonary hemorrhage in patients with systemic lupus erythematosus. Curr Respir Med Rev 2009, 5:49-54.

7. Zamora MR, Warner ML, Tuder R, Schwarz MI: Diffuse alveolar hemorrhage and systemic lupus erythematosus: clinical presentation, histology, survival, and outcome. Am J Med 2004, 76:192-202.

8. Hunninghake GW, Fauci AS: Pulmonary involvement in the collagen vascular disease. Am Rev Respir Dis 1997, 119:471-503.

9. Emlen W: Systemic lupus erythematosus and mixed connective tissue disease. J Allergy Clin Immunol 1993, 13:291-311.

10. Tze-Yi SY: Diffuse alveolar hemorrhage. Am J Med 2007, 16:12-122.

11. Kamen DL, Strange C: Pulmonary manifestations of systemic lupus erythematosus. Clin Chest Med 2010, 31:479-488.

12. Badsha $\mathrm{H}$, The $\mathrm{CL}$, Kong KO, Lian TY: Pulmonary hemorrhage in systemic lupus erythematosus. Semin Arthritis Rheum 2003, 33:414-421.

13. Abud MC, Diaz JE, Alarcon SD: Fatal pulmonary hemorrhage in systemic lupus erythematosus. J Rheumatol 1982, 12:558-561.

14. Byrd RB, Trunk G: Systemic lupus erythematosus presenting as pulmonary hemosiderosis. Chest 1976, 64:120-129.

15. Marino CT, Pertschuk LP: Pulmonary hemorrhage in systemic lupus erythematosus. Arch Intern Med 1981, 141:201-203.

16. Travis WD, Colby TV, Lombard C, Carpenter HA: Clinic pathologic studies of 34 cases of diffuse pulmonary hemorrhage with lung biopsy confirmation. Am J Surg Pathol 1990, 14:1112-1125.

17. Hughson MD, He ZJ, Henegar J, McMurray RR: Alveolar hemorrhage and renal microangiopathy in systemic lupus erythematosus: immune complex small vascular injury with apoptosis. Arch Pathol Lab Med 2001, 125:475-483.

18. Leatherman JW: Immune alveolar hemorrhage. Chest 1997, 91:891-897.

19. Schwab EP, Schumacher HR, Freundlich B, Callegari PE: Pulmonary alveolar hemorrhage in systemic lupus erythematosus. Semin Arthritis Rheum 1993, 23:8-15.

20. Nellessen CM, Pöge U, Brensing KA, Sauerbruch T, Klehr HU: Diffuse alveolar hemorrhage in a systemic lupus erythematosus patient successfully treated with rituximab: a case report. Nephrol Dial Transplant 2008, 23:385-386.

21. Santos AS, Mandell BF, Fessler BJ: Alveolar hemorrhage in systemic lupus erythematosus: presentation and management. Chest 2000, 118:1083-1090.

22. Koh WH, Thumboo J, Boey ML: Pulmonary haemorrhage in Oriental patients with systemic lupus erythematosus. Lupus 1997, 6:713-716.

23. Olson A, Schwarz M: Diffuse alveolar hemorrhage. Lupus 2007, 13:318-320. 
24. Colby TV, Fukuoka J, Ewaskow SP, Helmers R, Leslie KO: Pathologic approach to pulmonary hemorrhage. Ann Diagn Pathol 2001, 5:309-319.

25. Tze-Yi SY: Diffuse alveolar hemorrhage. Ann Diagn Pathol 2008 17:94-105.

26. Raptis A, Mavroudis D, Suffredini A, Molldrem J, Rhee FV, Childs R: High-dose corticosteroid therapy for diffuse alveolar hemorrhage in allogeneic bone marrow stem cell transplant recipients. Bone Marrow Transplant 1999, 24:879-883.

27. Speck U: Diffuse alveolar hemorrhage syndromes. Curr Opin Reumatol 2001, 13:12-17.

28. Mendoza AC, Moreno R, Cuevas E, Borja A: Treating severe systemic lupus erythematosus with rituximab. Reumatol Clin 2009, 5:147-152.

29. Hedner U: Recombinant factor Vlla (NovoSeven) as a hemostatic agent. Dis Mon 2003, 49:39-48.

30. Pastores SM, Papadopoulos E, Voigt L, Halpern NA: Diffuse alveolar hemorrhage after allogeneic hematopoietic stem-cell transplantation: treatment with recombinant factor VIla. Chest 2003, 124:2400-2403.

31. Hicks K, Peng D, Gajewski JL: Treatment of diffuse alveolar hemorrhage after allogeneic bone marrow transplant with recombinant factor VIla. Bone Marrow Transplant 2002, 30:975-978.

32. Henke D, Falk RJ, Gabriel DA: Successful treatment of diffuse alveolar hemorrhage with activated factor VII. Ann Intern Med 2004, 140:493-494.

33. Sabharwal AK, Bajaj SP, Ameri A, Tricomi SM, Hyers TM, Dahms TE: Tissue factor pathway inhibitor and von Willebrand factor antigen levels in adult respiratory distress syndrome and in a primate model of sepsis. Am J Respir Crit Care Med 1995, 151:758-767.

34. Heslet L, Nielsen JD, Levi M: Successful pulmonary administration of activated recombinant factor VII in diffuse alveolar hemorrhage. Crit Care 2006, 10:1-6.

35. Carrillo ER, Elizondo AS, Sánchez ZJ, Carrillo CJ: Hemorragia alveolar secundaria a lupus eritematoso generalizado, tratada con factor VII recombinante activado. informe de un caso y revisión de la literatura. [Alveolar hemorrhage secondary to lupus erythematosus treated with recombinant activated factor VII. Report of a case and review of the literature.]. Gac Med Mex 2007, 143:83-86.

36. Grochova M, Kalnasova B, Firment J, Olejarova I, Roland R, Lazurova I: Pulmonary administration of activated recombinant factor VII. Bratis/ Lek Listy 2011, 112:29-33.

37. Dabar G, Harmouche C, Jammal M: Efficacy of recombinant activated factor VII in diffuse alveolar haemorrhage. Rev Mal Respir 2011, 28:106-111.

38. Estella A, Jareño A, Perez-Bello FL: Intrapulmonary administration of recombinant activated factor VII in diffuse alveolar haemorrhage: a report of two case stories. Cases J 2008, 12:150-152.

39. Enomoto $M$, Thorborg P: Emerging off-label uses for recombinant activated factor VII: grading the evidence. Crit Care Clin 2005, 21:611-632.

40. Hoffman M, Monroe MD III: The action of high-dose factor VIla in a cell-based model hemostasis. Dis Mon 2003, 49:1-7.

41. Veldman A, Hoffman M, Ehrenforth S: New insights into the coagulation system and implication for new therapeutic options with recombinant factor VIla. Curr Med Chem 2003, 10:797-811.

42. Chang SJ, Yen YS, Huo AP, Lee SS, Huang DF: Acute massive pulmonary hemorrhage after craniotomy in a patient with systemic lupus erythematosus. Mikrobiol Zh 2005, 8:69-72.

43. Quintana DM, Sánchez CM, García LA: Factor VII activado recombinante [Recombinant activated factor VII]. Med Intensiva 2007, 31:326-330.

44. Macdonald JA, Fraser JF, Foot CL, Khoa T: Successful use of recombinant factor VII in massive hemoptysis due to community-acquired pneumonia. Chest 2006, 130:577-579.

45. Girolami B: Arterial and venous thrombosis in rare congenital bleeding disorders: a critical review. Haemophilia 2006, 12:345-351.

46. Mayer S: Recombinant activated factor VII for acute intracerebral hemorrhage. NEJM 2005, 352:777-785.

47. Mayer S: Efficacy and safety of recombinant activated factor VII for acute intracerebral hemorrhage. NEJM 2008, 358:2127-2137.
48. Thomas R: Thromboembolic complications associated with factor VIla administration. J Trauma 2007, 62:564-569.

49. Hardy JF: Efficacy and safety of recombinant activated factor VII to control bleeding in nonhemophiliac patients: a review of 17 randomized controlled trials. Ann Thorac Surg 2008, 86:1038-1048.

doi:10.1186/s40560-014-0047-2

Cite this article as: Esper et al:: Treatment of diffuse alveolar hemorrhage secondary to lupus erythematosus with recombinant activated factor VII administered with a jet nebulizer. Journal of Intensive Care 2014 2:47.

\section{Submit your next manuscript to BioMed Central and take full advantage of:}

- Convenient online submission

- Thorough peer review

- No space constraints or color figure charges

- Immediate publication on acceptance

- Inclusion in PubMed, CAS, Scopus and Google Scholar

- Research which is freely available for redistribution 